\title{
Natural Goodness without Natural History
}

Parisa Moosavi

pmoosavi@yorku.ca

\begin{abstract}
Neo-Aristotelian ethical naturalism purports to show that moral evaluation of human action and character is an of evaluation of natural goodness - a kind of evaluation that applies to living things in virtue of their nature and based on their form of life. The standard neo-Aristotelian view defines natural goodness by way of generic statements describing the natural history, or the 'characteristic' life, of a species. In this paper, I argue that this conception of natural goodness commits the neo-Aristotelian view to a problematic anti-individualism that results in the wrong assessment of individuals with uniquely adaptive adjustments. I then offer an alternative account of natural goodness that avoids this problem. Instead of relying on generic statements about a species, my account defines natural goodness based on counterfactual conditionals describing the modal properties of a single individual. I argue that this modal-explanatory account gives a conception of natural goodness that is more intuitively plausible and better suited to capture the diversity and plasticity distinctive of life.
\end{abstract}

Keywords: Neo-Aristotelian Naturalism. Natural Goodness. Natural History. Individualism. Teleological Explanation. Invariance.

\section{Introduction: Virtue as Natural Goodness}

According to neo-Aristotelian ethical naturalism, moral evaluation of human action and character shares a conceptual structure with evaluations of goodness and defect in other living things, including plants and animals. Foot (2001), Hursthouse (1999), and other proponents of the view argue that moral goodness is an instance of natural goodness in human beings, where natural goodness denotes a kind of evaluation that applies to living things and their parts and aspects in virtue of their nature and based on their form of life. Thus, neo-Aristotelians argue that moral virtue in human beings is akin to the deep root of an oak tree. In the same way that deep roots are naturally good in an oak tree because they enable it to flourish qua oak, moral virtues like justice and benevolence are naturally good in a human being because they enable her to flourish qua human. 
The first step in defending neo-Aristotelian naturalism is giving an account of natural goodness. Foot (2001) characterizes natural goodness as a form of evaluation that is exclusively attributable in the case of living things, and evaluates their parts and aspects based on standards determined by their form of life. She argues that almost anything can be evaluated in a context that sufficiently relates it to human concerns. But evaluations of natural goodness are distinctive in that they are intrinsic: they apply to the parts and aspects of living things independently of the interests of humans or any other external party. They only depend on the relation of an individual organism to its own form of life (2001, p. 27). What is naturally good in the life of oaks is good not because of how we happen to evaluate them, but simply because of the nature of the organism itself. Thus, evaluations of natural goodness are based on standards that are constitutive of a form of life. Given the nature of oaks as heavy trees, having deep and sturdy roots is constitutive of what it is to flourish qua oak. Similarly, neo-Aristotelians argue, given our nature as self-conscious human beings with a particular form of practical rationality, moral virtue is constitutive of what it is for us to flourish qua human being.

Neo-Aristotelian naturalism has been subject to ardent critical discussion. One prominent line of objection questions whether evaluations of natural goodness can be at the same time compatible with modern evolutionary biology and suitable for giving an account of moral virtue. Critics appeal to an evolutionary account of biological function and human life to question whether substantive virtues like justice and benevolence are instances of natural goodness in human beings (Fitzpatrick, 2000; Andreou, 2006; Millgram, 2009; Millum, 2006; Woodcock, 2009; Lewens, 2010; Odenbaugh, 2017). Neo-Aristotelians respond, however, that this objection relies on a mistaken interpretation of their view, where natural goodness is reduced to evolutionary biological functioning. They argue that natural goodness is based on a different notion of function-distinct from that of a biological adaptation - that is at the core of conceptualizing living things as living (Hacker-Wright, 2009; Lott, 2012a). The natural good of a kind of organism captures the characteristic way of life and flourishing of the organism, which cannot be deduced from the facts of evolution. Particularly in the case of human beings, since the characteristically human way of life involves the exercise of practical reason, forming the right conception of human nature requires an understanding of the norms of practical reason (Lott, 2012b). This is why empirical studies of our evolutionary history are not enough to give us an account of natural goodness in human beings. 
It's worth noting that neo-Aristotelian naturalism, construed in this way, is different from reductive forms of ethical naturalism in that it is compatible with the epistemic autonomy of ethics. ${ }^{1}$ In other words, it is not an ambition of the neo-Aristotelian view to offer a derivation of substantive moral virtues from non-evaluative, independently-recognizable facts. Arguably, it's the task of normative theory to work out the right substantive conception of human flourishing and moral virtue. What the view offers is rather an account of moral virtue in terms of an already evaluative conception of human nature, which nonetheless places morality on a par with evaluative patterns found in the lives of animals and plants. By presenting an account of moral goodness as natural goodness, neo-Aristotelians aim to show that moral evaluation is an instance of a familiar type of evaluation that we frequently make and accept in the case of non-human living things. Thus, they aim to show that moral goodness is not "a special kind of non-natural property" (Foot, 2001, p.6), but rather continuous with the natural domain of life. ${ }^{2}$

While I am sympathetic to the neo-Aristotelian project, I will argue that the conception of natural goodness that is at the core of the most paradigmatic forms of the view is in need of

${ }^{1}$ This is, roughly, the thesis that non-ethical evidence (such as evidence from biological sciences) is not relevant to the epistemic justification of "pure", or "non-mixed", ethical claims. (see Maguire, 2017, for a more precise account and discussion of various types of autonomy). Note that neo-Aristotelian naturalists have frequently pointed out that their view preserves the autonomy of ethics from biology (see Thompson, 2004, p. 72; Lott, 2012b, p. 418-421).

${ }^{2}$ Of course, in order to fully defend this view, neo-Aristotelians need to show that at least some evaluations of natural goodness in the case of plants and animals are objectively true and correctly represent the nature of reality. This is a claim that has been contested, particularly because neo-Aristotelians insist that the natural good of an organism cannot be reduced to evolutionary fitness. Some critics have argued that the neo-Aristotelian notion of natural goodness is part of an outdated conception of living things that should be rejected in light of the scientific account given by evolutionary biology (see Fitzpatrick, 2000; Odenbaugh, 2017). Neo-Aristotelians respond, however, that evolutionary biology is only concerned with explaining certain aspects of living things-namely their evolutionary history - and does not offer a satisfactory account of the nature of living things as living. They argue that accounting for the nature of living things as living requires presupposing an evaluative conception of their way of life, which commits us to the notion of natural goodness. See Hacker-Wright (2009, pp. 316-317), Lott (2012a, pp. 374375), and Moosavi (2019) for promising attempts to defend the neo-Aristotelian concept of natural goodness against this objection. 
revision. Foot fleshes out her account of natural goodness further and specifies that evaluations of natural goodness are based on the characteristic life of the species to which an organism belongs. In doing so, she relies on Thompson's (1995; 2008) account of the characteristic life of a species, or-to use Thompson's term-a life-form. On Thompson's account, members of a life-from share a natural history that can be represented in generic statements describing the characteristic elements, aspects, and phases of their kind of life. The natural history of the oak life-form, for instance, can be described in statements such as "oak trees have deep roots", "they produce acorns in the fall", and so on. This natural history then sets the standards for evaluating the parts and aspects of instances of the life-form as naturally good or defective. Thus, what explains the fact that the deep roots of the oak tree in my back yard are naturally good, on this view, is the natural history of the oak life-form.

The resulting natural-historical understanding of natural goodness is the focus of this paper. Although neo-Aristotelians typically use 'natural goodness' as synonymous with the FootThompson understanding of natural goodness in terms of natural history, I will draw a distinction between the general concept of natural goodness as an intrinsic and constitutive evaluation of living things based on their form of life, and the specific, natural-historical conception of this concept presented by Foot and Thompson. My aim is to argue that the natural-historical account is neither the only possible account of natural goodness nor the most plausible one. I will propose an alternative account of natural goodness that makes no reference to the natural history of a lifeform, and I will argue that it fares better than the natural-historical account in capturing intuitions regarding intrinsic and constitutive evaluations of living things. So, from here on, I preserve the term 'natural goodness' for the general concept of an intrinsic and constitutive evaluation of living things based on their form of life; and I use 'natural-historical goodness' or 'the natural-historical account of natural goodness' to refer to the specific account of this concept given by Foot and Thompson. ${ }^{3}$

\footnotetext{
${ }^{3}$ It's worth noting that giving an account of natural goodness is worthwhile regardless of whether the neo-
} Aristotelian metaethical project will succeed. Even if it turns out that moral virtue is in fact not an instance of natural goodness, it would be helpful to understand what natural goodness is. It's a concept that seems to be at the core of understanding the nature of life, and is potentially relevant for giving an account of other important concepts such as welfare, health, and disability. 
In what follows, after a more in-depth discussion of the natural-historical account, I argue that this account leads to the wrong assessment of a class of individuals whose uniquely adaptive adjustments set them apart from other members of the species to which they belong. I argue that this problematic outcome results from the fact that the natural-historical account is committed to anti-individualism - roughly, the thesis that the standards of natural goodness are not determined by lower-level facts about the individual organism itself. This is an aspect of the neo-Aristotelian view that has not been critically discussed. I argue that the commitment of the natural-historical account to anti-individualism is both problematic and unnecessary. I then propose an alternative account of natural goodness that does not share this commitment and hence can avoid the mischaracterization of individuals with uniquely adaptive adjustments.

\section{The Natural-Historical Account of Natural Goodness}

Let's have a closer look at the natural-historical account. As I mentioned above, on this account, the standards for evaluating the parts and aspects of a living organism depend on the natural history of its life-form. The concept of a life-form, which is introduced by Thompson (1995; 2008), is defined in terms of a particular form of thought that we use in relation to the domain of life. This form of thought is manifested in the kind of generic descriptions that we typically encounter in a nature documentary or a field guide — statements such as "the bobcat has four legs" or "cherries bloom in spring". Thompson calls these statements natural-historical judgments. The general form

of natural-historical judgments is something like "the $S$ is/has/does $F$ ", "Ss are/have/do $F$ ", or "an $S$ is/has/does $F$." Thompson argues that natural-historical judgments have a distinctive form of generality that is neither universal nor statistical. They articulate the characteristic elements, aspects, and phases in the life of a kind of living thing. But they are neither universal generalizations about all instances nor statistical generalizations about most instances of the kind. The truth of a natural-historical judgment about life-form $S$ is consistent with some or even most instances of $S$ not matching the description expressed in the judgment. For instance, "the bobcat has four legs" can be true even if most bobcats lose one of their legs in an accident. According to Thompson, what we can infer about such non-conforming instances is that there is something defective about them: a bobcat with only three legs is defective in that it doesn't have four legs. In this way, natural-historical judgments provide a basis for evaluations of natural goodness and defect. The natural history of a life-form, which is captured by the set of true natural-historical 
judgments about the life-form, determines what is naturally good or defective in the life of members of the life-form.

A few clarifications about natural-historical judgments are in order. Although these judgments are generics, not every generic judgment is a natural-historical judgment. Broadly speaking, generic judgments pick out patterns of regularity that characterize instances of a kind; but they don't necessarily underwrite inference to evaluative judgments. "Minnesota winters are cold", for instance, is a generic judgment that doesn't underwrite evaluative inferences: a mild winter in Minnesota wouldn't necessarily be so bad. If natural-historical judgments are to underwrite evaluative inferences, they need to be more than mere generics. In fact, on Thompson's account, natural-historical judgments meet several other criteria beside genericity.

First off, natural-historical judgments have a teleological character. Thompson describes natural-historical judgments as a specific subclass of generics that are "teleologically articulable" $(2008,79)$. This means that natural-historical judgments can be connected with each other in teleological relations. Take, for instance, "the bobcat hunts at dawn and dusk". As a naturalhistorical judgment, this statement can be connected with another natural-historical judgment about bobcats, e.g., "the bobcat stalks prey with stealth", such that we can say: "the bobcat hunts at dawn and dusk in order to stalk prey with stealth". This natural teleological judgment describes a teleological relation between two aspects of the life-form, where one is characterized as a means toward the other. Note that "Minnesota winters are cold" does not have this teleological character, which is why it is not a natural-historical judgment. Natural-historical judgments identify characteristic aspects of the life-form that serve a purpose and can be described a means toward other characteristic aspects of the life-form.

Moreover, each natural-historical judgment about a life-form must be teleologically related to other natural-historical judgments not just as a means, but also ultimately as an end. "The bobcat hunts at dawn and dusk", for instance, describes a characteristic activity that is not only a means toward further ends such as stalking prey, but also an end toward which other aspects of the lifeform such as having sharp eyesight are a means. We can say: "the bobcat has sharp eyesight in order to hunt at dawn and dusk", to describe a teleological relation in which hunting at dawn and dusk appears as an end. To see why having the teleological relation in the reverse direction is necessary, consider a breed of domestic sheep raised for their wool, on which shearing is regularly practiced. Suppose that unlike wild sheep that only grow enough wool for protection from cold, 
this breed of sheep grows so much wool that it needs to be sheared to avoid overheating. Although it might be true that "the sheep has short wool in summer", this is not a true natural-historical judgment about this domestic breed of sheep, even if having short wool serves a purpose in the life of the sheep. ${ }^{4}$ The reason is simply that having short wool is not an end toward which any other characteristic aspect of the sheep is a means.

Lastly, natural-historical judgments are different from generic statements about artifacts and crafts, which also have a teleological character. Artifactual judgments like "cars have a carburetor" and "cars burn fuel" can be teleologically connected. But these judgments do not describe lifeforms, and they cannot be the basis for evaluations of natural goodness. As we saw earlier, evaluations of natural goodness are intrinsic - they apply to parts and aspects of living things independently of the interest of humans or any external party. In the case of artifacts and crafts, although we can evaluate their parts and mechanisms, the basis for evaluation is ultimately something about us. Cars are ultimately for our transportation, and if we evaluate a car's carburetor based on how it enables the car to burn fuel, this evaluation is not independent from our own ends and interests. To distinguish natural-historical judgments from artifactual judgments, Thompson suggests that the truth of teleological judgments about artifacts "presupposes that someone makes or has made the corresponding judgment, or at least some others belonging to the same system of judgments" (2008, p. 80). It simply cannot be true that "cars have a carburetor in order to burn fuel" unless someone has made this judgment or at least some other judgment regarding cars. In contrast, natural-historical judgments can be true without anyone knowing about them or making any kind of judgment about the life-form they describe. In fact, as Thompson points out, unrecognized life-forms are common.

To sum up, the statement "the $S$ is/does/has $F$ " is a true natural-historical judgment about lifeform $S$, describing natural-historical characteristic $F$, if and only if:

(1) Genericity: "The $S$ is/does/has $F$ " is a true generic.

(2) Teleology: There is a natural-historical characteristic of $S, G$, such that "The $S$ is/does/has $F$ in order to be/do/have $G$ " is a true generic. There is also a natural-historical characteristic of $S, H$, such that "The $S$ is/does/has $H$ in order to be/do/have $F$ " is a true generic.

\footnotetext{
${ }^{4}$ Note that failure to have short wool—say, due to lack of shearing — would not be a defect in this breed of sheep, even if it would be disadvantageous.
} 
(3) Independence: The truth of natural teleological judgments about $S$ does not presuppose that anyone makes these judgments or any other judgments about $S$.

Now, the teleological connective in condition (2) needs further clarification. The way Thompson conceives of the connective, it is simply used to organize the elements of a natural history, without having anything to do with "the category of intention and psychic teleology" (2008, p. 78). Natural teleological judgments articulate the relations of dependence that hold among the elements and aspects of a given life-form. They specify which elements and aspects of a life-form provide the conditions required for other elements and aspects to arise. In Thompson's words, the teleological connective "simply expresses the concept that is converse to this conception of dependence" (2008, p. 79). So, the judgment "the bobcat hunts at dawn and dusk in order to stalk prey with stealth" simply expresses that stalking prey with stealth depends on hunting at dawn and dusk.

It may seem as though this dependence relation among the elements of a natural history can be interpreted as a mere causal dependence relation. On this interpretation, "The $S$ is/does/has $F$ in order to be/do/have $G$ " simply means that $F$ and $G$ are two characteristic features of life-form $S$, where $F$ causes $G$. However, this interpretation would make the natural-historical account inadequate as an account of natural goodness. If all that is required for a generic statement to be teleologically connected to another generic statement was that they describe aspects of a kind that are causally linked, many non-living kinds would be the subject of true natural-historical judgments. Volcanoes, for instance, can be described by generic statements such as "volcanoes are formed when magma from the earth's upper mantle comes to the surface" and "volcanoes erupt when pressure builds up". ${ }^{5}$ Moreover, the characteristic features and phases described in these generic statements causally depend on each other. In fact, geologists talk about the 'life-cycle' of a volcano, describing the stages volcanoes go through as they form, become active, erupt, and become extinct. Nonetheless, it would be a mistake to evaluate volcanoes as good or defective based on how well they exhibit this characteristic life-cycle. The causal dependence relation between the different stages that they go through does not amount to a teleological relation of the right type, and it would be misleading to say things like "volcanoes are formed in order to erupt".

${ }^{5}$ Note that these statements will remain true even if as a result of climate change volcanoes do not always exhibit this pattern perfectly. 
For natural-historical judgments to serve as the basis for evaluations of natural goodness, the dependence relation among the elements of a natural history cannot be interpreted as a mere causal relation. The relevant notion of teleological dependence implies that the characteristic feature described in a natural-historical judgment contributes to something that is a genuine good of the life-form. What is missing in the case of volcanoes is that the contribution of the characteristic elements and stages of the system cannot be plausibly viewed as good, which is why the causal dependence relations that they instantiate do not amount to the relevant kind of teleological relation. Thus, the truth of "S is/does/has $F$ in order to be/do/have $G$ " requires not only that $F$ causally contribute to $G$, but also that $F$ and $G$ are good in the life of $S$.

Incorporating this interpretation of the teleological dependence relation in our conditions (2) and (3) above, the truth conditions for natural-historical judgments can be articulated as follows. The statement "the $S$ is/does/has $F$ " is a true natural-historical judgment about life-form $S$, if and only if:

(1) Genericity: "The $S$ is/does/has $F$ " is a true generic.

(2) Teleology: "The $S$ is/does/has $F$ in order to be/do/have $G$ " and "The $S$ is/does/has $H$ in order to be/do/have $F$ " are true generics, where $G$ and $H$ are natural goods in $S$.

(3) Independence: The truth of natural teleological judgments about $S$ does not presuppose that anyone makes these judgments or any other judgments about $S$.

It is worth noting that Foot's discussion of the teleological dimension of natural-historical judgments actually suggests a similar interpretation of teleology. In her discussion of what she sees as "a gap" in Thompson's account, Foot argues that in order to support inference to evaluations of natural goodness, natural-historical judgments must describe a feature that serves a function, or plays a part, in the life characteristic of the life-form. What counts as "the life" of a kind of living thing, however, is understood in terms of essential goods such as survival and reproduction. Foot believes that for plants and non-human animals, "the life" characteristic of the life-form has to do, directly or indirectly, with development, self-maintenance, and reproduction. In her view, a statement like "the blue tit has a blue patch on its head" does not support inference to evaluative judgments, because the color of the head plays no part in any of these aspects of "the life" of the bird. In the case of human beings, of course, essential goods go beyond this list and are much more diverse. In fact, one could argue that even in the case of non-human living things, there 
can be essential goods other than the three goods that Foot considers. ${ }^{6}$ But regardless of what exactly the goods of a given kind of living thing consist in, it's important to see that the teleological dependence relations expressed in condition (2) have to be understood in terms of these goods. In Foot's words, for any element of the natural history, we must be able to ask: "what's the point of it?" and "what good does it do?" (Foot, 2001, pp. 30-31). Unless a feature makes a characteristic contribution toward a good, it does not have a place in the natural history of the life-form.

Now we are finally in a position to articulate the natural-historical account. We saw that on this account, natural-historical judgments are the basis for evaluations of natural goodness, such that a given feature in an organism is naturally good if and only if it matches the characteristic feature expressed in a true natural-historical judgment about the individual's life-form, and it is naturally defective when it doesn't so match. Thus, the natural-historical account can be formulated as follows:

For any individual organism $x$ that is an instance of life-form $S$, being/doing/having $F$ is a natural good if and only if:

(1) Genericity: "The $S$ is/does/has $F$ " is a true generic statement.

(2) Teleology: "The $S$ is/does/has $F$ in order to be/do/have $G$ " and "The $S$ is/does/has $H$ in order to be/do/have $F$ " are true generics, where $G$ and $H$ are natural goods in $S$.

(3) Independence: The truth of natural teleological judgments about $S$ does not presuppose that anyone makes these judgments or any other judgments about $S$.

There are a few things to note about this account. First, since the teleological component of the natural-historical account cannot be understood without presupposing an evaluative conception of "the life" of living things, the account does not offer a reduction of natural goodness. Purely non-evaluative criteria such as patterns of genericity or relations of causal dependence are not enough to determine the natural good of a life-form on this account. We rather need to presuppose an already evaluative conception of "the life" of a given kind of organism before we can identify the natural-historical judgments that are the basis evaluations of natural goodness. Thus, the account does not amount to a definition of natural goodness unless it is coupled with basic assumptions about at least some natural goods in the life of a given life-form.

${ }^{6}$ Hursthouse, for instance, considers enjoyment and freedom from pain among the characteristic goods in the life of sentient animals (1999, p. 200). 
However, the fact that the account does not reduce natural goodness in non-evaluative terms does not mean that it is uninformative or that it contributes nothing to our understanding of natural goodness. As mentioned earlier, neo-Aristotelian naturalism does not aim to offer a derivation of substantive moral virtues from non-evaluative facts. It rather aims to give an account of moral virtue in terms of an already evaluative conception of natural goodness in human beings, which nonetheless shows moral evaluation to be an instance of a familiar type of evaluation that characterizes plants and animals. The natural-historical account describes this familiar type of evaluation in non-reductive, yet informative terms. Although the account does not provide a straightforward derivation of natural goods from independently-recognizable facts, it does guide our theorizing once we have some plausible background assumptions about the goods of the organism. More specifically, it identifies genericity as a necessary condition for natural goodness, which informs how we interpret the background assumptions when applied to the specific case of an organism.

To see how the natural-historical account informs our theorizing, suppose we start with the plausible assumption that survival or self-maintenance is a natural good in the life of plants and animals. ${ }^{7}$ It's easy to see that this general idea is not enough to determine the specific parts and aspects that are naturally good in a given kind of organism. Almost any feature or aspect of an organism might contribute to survival under the right conditions, but we don't consider just any contribution to survival as an instance of natural goodness, and we don't consider just any failure to contribute to survival as an instance of natural defect. For example, a particular arrangement of fur on a tiger's face might discourage a hunter from shooting the tiger if the shape of fur happens to remind him of his mother's face. ${ }^{8}$ But we do not thereby evaluate this fur arrangement as naturally good. The natural-historical account explains why the fur arrangement does not qualify

${ }^{7}$ As mentioned earlier, Foot considers self-maintenance to be a good in the life of plants and animals, which is not to say that it is the only good or the ultimate good in their life. The good of self-maintenance has to be balanced against other goods in the life of the organism and achieved by its characteristic way of life. On Foot's account, for plants and non-human animals, the list of natural goods also includes reproduction and development. For human being, the elements that make up a good life are more diverse and interdependent, and are characteristically achieved by exercising practical reason (Foot, 2001, p. 42).

8 This example is adapted from Lott (2012b, p. 371). 
as a natural good by appealing to patterns of genericity: it's neither characteristic of tigers to have fur arrangements of this particular shape, nor characteristic of such fur arrangements to contribute to a tigers' survival. In contrast, a tiger's sharp eyesight or the ability to run fast not only contribute toward the tiger's survival, but also do so systematically and characteristically, by enabling the tiger to engage in other characteristic behaviors such as hunting prey. We can make true generic statements, saying "tigers run fast" or "tigers run fast in order to hunt prey". On the naturalhistorical account, this is why characteristics like running fast and having sharp eyesight are naturally good in the life of a tiger and lacking them is a defect. In this way, the account offers a basis for interpreting the parts and aspects of living things and making specific evaluations in view of general assumptions about the goods. ${ }^{9}$

\section{Natural-Historical Evaluations and the Problem of Anti-Individualism}

The natural-historical account has a lot of initial appeal. We do typically use generic judgments to describe and understand living things, and many instances of such judgments - e.g., cats having four legs, owls seeing in the dark, etc. - seem intuitively plausible. We also seem to rely on these judgments in making evaluations of individual organisms and what goes well or poorly in their life. However, although we find these judgments intuitively plausible, there is a question whether they are more than useful approximations or rules of thumb that we employ in our folk understanding of living things. Even if there is a sense in which many of our generic judgments about living things are true, it is not obvious that they provide a basis for evaluations of the right kind. Note that to provide a basis for evaluations of natural goodness-i.e., the kind of intrinsic evaluation that is constitutive of living things - natural-historical judgments need to identify aspects of a kind of organism that capture its nature as a living thing. It's not enough for these judgments to be merely true of a kind of living thing: it has to be essential to grasping its nature. My contention is that although in a great many cases natural-historical judgments do identify

\footnotetext{
${ }^{9}$ It should be noted that although I have used the good of survival as an example to demonstrate how the naturalhistorical account helps our theorizing, the account (as formulated above) is not tied to this or any other general assumptions about the natural goods. The background assumptions about the goods that are coupled with the naturalhistorical account need to be independently plausible, and it is no part of the neo-Aristotelian view that they can be simply derived from the facts of evolution.
} 
aspects of living things that can underwrite evaluations of natural goodness, this is not always the case. Here, I introduce a class of cases where the natural-historical account does not capture what intuitively seems to be the right intrinsic assessment of a living organism.

Consider the judgment "goats have four legs", which is a good candidate for a true naturalhistorical judgment about goats. Not only is having four legs a characteristic feature that is generally observed in goats, it plays a role in other aspects of the goats' natural history such as how they stand and how they walk. According to the natural-historical account, this naturalhistorical judgment implies that a goat without four legs is naturally defective, which is an assessment that intuitively seems plausible in the case of most goats without four legs. However, consider now the real-life case of a two-legged goat described in 1942 by morphologist E. J. Slijper. West-Eberhard (2005) writes about this goat in her discussion of the role of developmental plasticity in the origin of species differences. This goat was born without forelimbs, but it adapted to its condition in unexpected ways. It developed several behavioral and morphological specializations similar to those of kangaroos and other bipedal mammals, including enlarged hind limbs, a curved spine, and an unusually large neck. As a result, the goat learned to hop around using its hind legs alone. As West-Eberhard's points out, the correlated shift in the goat's morphology and behavior led to "the well coordinated production of a complex and individually advantageous adjustment, producing a novel phenotype with little or no genetic change" (2005, p. 6545). The goat lived for a year before it died in an accident unrelated to its physical condition. Let's call this goat 'Hopper' to signify its unique way of moving around. I will argue that the case of Hopper presents a challenge to the natural-historical account. Since Hopper did not have four legs, the natural-historical account evaluates this goat as naturally defective. But given that the goat seems to have been able to manage perfectly well without four legs, it's not clear why we should accept this evaluation. ${ }^{10}$

One might try to defend the natural-historical evaluation of Hopper by arguing that even though the goat could hop on two legs, its way of movement was not as effective as normal goats. It seems plausible that a goat that hops on two legs would not be able to get around as fast or as easily as normal goats running on four. However, note that regardless of whether this was in fact

${ }^{10}$ For further discussion of Slijper's goat, see Amundson (2000, p. 39-40). Amundson uses this example to argue against the legitimacy of the concept of normal function in biology. 
the case with Hopper, the natural-historical account is not sensitive to how fast or easily a twolegged goat can move around. Even if Hopper was able to move with the same speed and ease as ordinary goats, the account would evaluate it as defective due to its difference in how it moves. What makes "goats have four legs" a true natural-historical judgment and a basis for naturalhistorical evaluation is that having four legs is a characteristic feature of goats that characteristically contributes to other characteristic aspects of their life like movement and finding nutrition. Even if Hopper could realize these other characteristic aspects of a goat's life with only two legs, its way of achieving them would not be the characteristic way.

Moreover, even if as a matter of fact Hopper was slower than other goats, it is not obvious that this difference in speed should constitute a defect. Presumably, ordinary four-legged goats also vary in their speed depending on other factors like their size. Unless Hopper's slowness is debilitating and restrictive, it seems arbitrary to consider its relative slowness as a defect. Note that the natural-historical account does not consider ordinary goats defective for falling short of the speed exhibited by other species like cheetahs and lions. Even if the ability to run as fast as a lion would be an advantage in the life of a goat, the account does not evaluate all goats as naturally defective or naturally worse-off than faster species. And this is for a good reason: natural goodness is an evaluation of living things based on standards internal to their own form of life; not based on what would have been optimal or ideal for them. A cheetah's ability to run fast or an eagle's ability to fly would be external and irrelevant standards for evaluating a goat. Similarly, a four-legged goat's ability to run with a certain speed seems like an external and irrelevant standard for evaluating Hopper. Given that Hopper diverges significantly from ordinary goats in its morphology and method of locomotion, it seems to merit a different standard of evaluation based on its own modified form rather than the form of other goats.

Note that the problem with the natural-historical assessment of Hopper is not merely that it misidentifies the legs as defective, but also that it fails to identify the good of many aspects of the goat's morphology. Hopper had a dorsoventrally compressed ribcage, a swayed back, and dorsally located clavicles and scapulae, which together enabled the goat to keep its upright posture and walk on two legs. Any of these features would likely be a defect in ordinary goats, but in Hopper, they made a crucial contribution to the goat's achieving movement and maintaining its way of life. It seems plausible to consider the presence of these features in Hopper as naturally good, and their loss as a defect. The natural-historical account, however, is not able to make any such assessment. 
It treats all the peculiar aspects of Hopper as instances of natural defect in the same way that it treats them as defect in ordinary goats.

Proponents of the natural-historical account might respond by contesting my original assumption that "goats have four legs" is a true natural-historical judgment. They might argue that once we encounter the case of Hopper, we need to revise this judgment, because we learn that having two legs is also an acceptable way for goats to be. They might suggest, for instance, that we could accommodate the case of Hopper by simply weakening our initial natural-historical judgment to something like "goats have at least two legs". However, it's easy to see that this revision won't help, because the resulting standard of evaluation would be overly permissive. The judgment "goats have at least two legs" implies that having only two legs is acceptable in any goat, regardless of whether the goat has made the distinctive developmental adjustments observed in Hopper. So, it would fail to capture the fact that having only two or three legs constitutes a defect in an ordinary goat.

A more promising strategy for accommodating the case of Hopper would be to argue that the life-form goat consists of two sub-kinds that have different characteristics and can be described in different natural-historical judgments. Polymorphism - the occurrence of multiple distinct phenotypes in the population of a species - is a commonly observed phenomenon among living things. And there is no reason to think that the natural-historical account cannot handle polymorphism. When there are different sub-kinds within a life-form, natural-historical judgments can be articulated in such a way that they specify different characteristics based the sub-kind to which their instances belong. So, my opponent could argue that upon encountering Hopper, we can recognize a new sub-kind of goats-bipedal goats — which differ from other goats not only in the number of their legs but also in various other characteristics like the shape of their spine and how they move. We can describe this sub-kind in natural-historical judgments such as "bipedal goats have two legs," "have a curved spine," "move by hopping around," while making different natural-historical judgments about quadrupedal goats. In this way, the natural-historical account can avoid mischaracterizing Hopper as defective without offering a standard of evaluation that is overly permissive for other goats.

However, although dividing a life-form into different groups makes sense in the case of established sub-kinds that are observed regularly among the members of the life-form, it won't help to address the problem if the alternative form is unique to a single individual. If the case of 
Hopper is unprecedented and unique among goats, it's not clear why we should accept "bipedal goats have two legs" as a true natural-historical judgment. There is no reason to think bipedalism marks a sub-kind of goats as opposed to a merely accidental feature of Hopper. Remember that the natural-historical account relies on generic patterns observed among members of a life-form to distinguish between characteristic and accidental aspects of an organism. As we saw earlier with Lott's example of the tiger whose face resembles a hunter's mother's face, not just any trait that contributes to a good in the life of an organism is a characteristic trait. The natural-historical account does not consider the arrangement of fur on the face of Lott's tiger to be characteristic of tigers, because the trait is not observed with any sort of regularity among tigers. "Cute-faced tigers have faces that resemble the face of a human female" is therefore not a true natural-historical judgment about a sub-kind of tigers. But by the same token, if the adaptive adjustment enabling Hopper to hop on two legs is unique to Hopper, we have no grounds for viewing bipedalism as a characteristic aspect of a sub-kind of goats. And in the absence of such grounds, the naturalhistorical account is committed to evaluating Hopper based on the same standard that applies to normal, four-legged goats.

This problematic implication of the natural-historical account results from its commitment to the rejection of a position that Thompson calls individualism. In his discussion of the concept of life, Thompson (2008) rejects the idea that whether an individual entity amounts to a living thing and whether its parts and processes amount to organs and vital operations is determined by lowerlevel facts about the region of space-time occupied by the individual. Instead, he argues that the representation of the individual as a living thing depends on the 'wider context' of its life-form, which goes beyond the individual and "is not fixed or determined by anything in the individual itself" (2008, pp. 50-51). As we saw earlier, Thompson defines a life-form as a special sort of kind or category that can be the subject of a natural-historical judgment (2008, p. 48). And for the reasons I explained with the example of Hopper, this conception of a life-form implies that the form of life of a living thing is characteristically shared between multiple instances of the lifeform, which excludes the possibility of life-forms with only one instance. As Thompson puts it, although it may not be a priori that "a life-form must have (or have had or be going to have) more than one bearer", we know of no other way for life-forms to be realized in nature as we know it to be (2004, n. 10). I take it that this is because we know of no other way to distinguish between characteristic and accidental aspects of the life of an organism. A class of individuals that are 
linked via reproduction realizes patterns of regularity that underwrite generic judgments describing the characteristic aspects of their life. But with merely a single individual, and in the absence of supernatural grounds such as a theological theoretical framework, there just isn't anything that can underwrites generic, natural-historical judgments. In the case of a swamp creature appearing as a result of a cosmic accident, for instance, Thompson argues that even if it is a molecule-formolecule replica of Thompson himself, we cannot view it as an instance of the human form or any other life-form. That is because without any connection to human beings or other life-forms, there is no wider context for assessing the individual, and it is underdetermined how its parts and aspects should be understood. It's underdetermined, for instance, whether the part that is the molecular equivalent of Thompson's left arm is really an arm or, say, a horribly deformed wing (2008, pp. 60-61).

To sum up, the natural-historical account gives an anti-individualist conception of natural goodness, according to which the standards of evaluation are not determined by lower-level properties of a single individual, and rather depend on patterns of regularity realized across multiple individuals sharing the same life-form. This means that an individual organism cannot be subject to a standard of natural goodness that is not shared by any other actual organisms. And I have argued that this requirement results in making the wrong assessment of individuals with a unique form. It should be noted that although I have focused on one illustrative example with the case of Hopper, the development of unique forms as a result of developmental plasticity is by no means a rare occurrence among living things. In fact, West-Eberhard argues that "the two-legged goat effect" is a widespread phenomenon (2003, p. 53). Developmental plasticity - the ability of organisms to change in response to external or internal environmental inputs during their development - is a distinctive feature of living things that plays an important role in originating evolutionary novelty. When a new phenotype arises as a result of genetic or environmental input, the plasticity of living organisms enables them to respond by developing other novel and highly adaptive phenotypes via phenotypic accommodation-the adaptive adjustment of various phenotypes in the organism to accommodate the new phenotype. If the genetic or environmental factor initiating the change is recurrent, the new phenotypes will spread and ultimately get genetically accommodated via natural selection. But clearly, whether a novel phenotype in a given organism is naturally good or defective does not have to depend on whether the phenotype gets 
spread in the population later. And we have seen that the natural-historical account is unable to identify an adaptive novel phenotype as naturally good unless it is multiplied across the species.

\section{Toward an Alternative Account of Natural Goodness}

My aim in the rest of the paper is to offer an alternative account of natural goodness that avoids the problematic commitment of the natural-historical account to anti-individualism. I will sketch a novel account that does not rely on generic judgments about a life-form, and instead grounds the distinction between goodness and defect in explanatory generalizations that describe an individual organism. In a nutshell, my account determines whether a part or an aspect of an organism is naturally good or defective based on the best explanation of the organism's various parts and aspects. In offering this account, I draw from Walsh's (2012; 2013) approach to teleological explanation. As we will see below, Walsh defends the status of teleological explanation as scientifically respectable by identifying a distinct kind of regularity in the modal profile of a purposive system that is empirically observable and explanatorily significant. In the next section, we will see how my account appropriates this distinct kind of regularity as a basis for evaluations of natural goodness. But let's start with an overview of Walsh's account first.

A teleological explanation explains the occurrence or the nature of some event or entity by citing the goal, end, or purpose to which it contributes. Despite the prevalence of teleological notions in biology, they are often considered problematic and associated with the pre-Darwinian view of life as the product of God's conscious design. As Walsh (2012; 2013) points out, modern scientific methodology is predominantly mechanistic. On the mechanistic worldview, every natural phenomenon has a productive cause, and to explain the phenomenon one adverts to the causal mechanisms that produce the phenomenon. Moreover, causal-mechanistic explanations are considered to be in principle exhaustive and complete: they apply to the occurrence of every event, and once completed, they leave no unexplained residuum. Because of this, contemporary philosophy of biology often tries to naturalize teleological explanations by offering a translation scheme that presents teleological explanation as a cryptic form of causal explanation. ${ }^{11}$ However,

${ }^{11}$ This usually involves citing natural selection as the causal mechanism that accounts for the explanatory role of function ascription. The selected-effect accounts of function (Millikan 1989; Neander 1991, Godfrey-Smith 1994), for instance, interpret the function of a trait as the effect for which past occurrences of the trait have been selected. 
Walsh argues that teleological explanation is a legitimate, non-redundant form of scientific explanation that is not reducible to causal explanation and captures a distinct kind of regularity in the world. On his view, for some events, fully understanding their place in the natural world requires that they are explained "twice over: once by appeal to the mechanisms that cause them and once by appeal to the purposes they subserve" (Walsh 2012, p. 174). To defend the status of teleological explanation as a distinct and legitimate form of scientific explanation, Walsh appeals to a prominent account of causal explanation given by Woodward $(2001 ; 2005)$.

According to Woodward, giving a causal explanation of a phenomenon requires identifying a set of conditions that make the difference between its occurrence and its non-occurrence. This involves identifying the phenomenon as part of what he calls an invariance relation, which is essentially a robust relation of counterfactual dependence between two states or events. A relation is invariant or stable across certain changes if it holds - up to some appropriate level of approximation-across those changes. If $x_{c}$ is genuinely a cause of $x_{e}$, we would expect the generalization describing how changes in $x_{c}$ are correlated with changes in $x_{e}$ to be invariant under at least some change in $x_{c}$ (Woodward, 2005, p. 239). ${ }^{12}$ This means that, for a range of circumstances, if we were to intervene to change the value of $x_{c}$, the value of $x_{e}$ would also change in a systematic way, such that the generalization describing the relation between $x_{c}$ and $x_{e}$ would continue to hold. ${ }^{13}$

They then appeal to the historical efficacy of natural selection to capture how functions explain the existence or prevalence of their function-bearers: the current occurrence of the functional trait is causally explained by the effect of the previous occurrences of the trait which gave the bearer a selective advantage.

${ }^{12}$ More accurately, we would expect them to be invariant under some interventions on $x_{c}$, where an intervention on $x_{c}$ with respect to $x_{e}$ is a change in the value of $x_{c}$ that changes $x_{e}$, if at all, only via a route that goes through $x_{c}$ and not in some other way.

${ }^{13}$ We can see that this is the case for Newton's law of universal gravitation. The generalization $F=G m_{1} m_{2} / r^{2}$ describes the relation between the magnitudes of two masses $m_{1}$ or $m_{2}$, the distance $d$ between them, and the value of the gravitational force they exert on each other. Not only does this generalization hold for the actual values of the variables in a given instance, it also continues to hold in a range of counterfactual circumstances under variations in the value of $m_{1}, m_{2}, d$, or $F$. 
Woodward argues that a generalization relating $x_{c}$ and $x_{e}$ that is invariant in this way enables us to explain $x_{e}$ in terms of $x_{c}$. The explanation shows how changes in explanandum counterfactually depend on changes in the factors cited in the explanans, i.e., how the explanandum would have been different if the factors cited in its explanans had been different.

Importantly, this account of explanation does not limit explanatory generalizations to what are often regarded as laws of nature. The invariance relation does not require that the generalization describing the relation between the two states is exceptionless or that it meets other traditional criteria for lawfulness such as breadth of scope and theoretical integration. All that is required for a generalization to be invariant is that it is stable under some range of interventions.

According to Walsh $(2012 ; 2013)$, just as a relation of counterfactual dependence holds between a cause and its effect, a distinct relation of the same form holds between a goal and the means to its attainment. On Walsh's view, although Woodward's invariance relation-which we may call causal invariance-always holds between a cause and effect, when the effect is also a goal and the cause is a means to attaining that goal, there is an additional invariance relation between the two, which holds in the reverse direction and underwrites a teleological explanation of the means in terms of the goal. Walsh $(2015$, p. 198) calls this additional invariance relation purposive invariance. He argues that while the causal invariance relation captures the counterfactual dependence of an effect on its cause, the purposive invariance relation captures the counterfactual dependence of cause (as a means) on the effect (as a goal).

We can see the difference between these two patterns of counterfactual dependence in an example. Suppose you are walking in a market when you notice that a store actually carries sweet lemons, a childhood favorite that you have had a hard time finding anywhere in town. Happy with this incident, you buy some lemons. ${ }^{14}$ Now, contrast this scenario with a different case where you already know that the store carries sweet lemons and you go to the market specifically to buy some lemon from the store. Although in both cases you buy sweet lemons as a consequence of going to the market, the patterns of counterfactual dependence are not the same. Both cases get the same causal explanation. In both cases, buying lemons is causally explained by going to the market. This is because the relation between going to the market and buying lemons exhibits causal

14 Walsh discusses a similar example adapted from Aristotle's Physics II.5 involving a man collecting subscriptions for a feast (Walsh, 2015, p. 193). 
invariance and continues to hold under certain changes in the conditions of your going to the store. For instance, if you had gone to the market wearing something else, you would still have bought the lemons. Or if you had gone to the market a little earlier in the day, you would have bought the lemons a little earlier in the day. However, in the second case, there is also a different invariance relation that supports additional counterfactuals. For instance, in the second case, if lemons were kept somewhere in the back not immediately noticeable to someone walking in the market, you would still have bought some. Perhaps even if it was another store carrying sweet lemons you would have gone to the other store instead and would still have bought them. Or if you were busy during the day and worried that the store might run out of lemons before you could walk there, you would have driven your car to the market instead. This additional pattern of invariance, which is absent in the first case, is due to the fact that in the second case there is a means-end relationship between going to the market and buying lemons. On Walsh's account, this different pattern of invariance underwrites a distinct form of explanation that is teleological explanation. And that is why, in the second case, we can explain your going to the market by pointing out that you go there in order to buy sweet lemons.

According to Walsh, the purposive invariance relation between a goal $x_{e}$ and a means $x_{c}$ exhibits stability under two kinds of changes. First, the relation between $x_{c}$ and $x_{e}$ is not disturbed by at least some changes in the initial conditions. Under a range of conditions, as long as $x_{e}$ is a goal, $x_{c}$ will occur as a matter of regularity such that $x_{e}$ occurs as a result. Second, under a range of conditions, if the goal $x_{e}$ is changed to $x_{e}{ }^{*}$, the means would correspondingly change, to $x_{c}{ }^{*}$, such that the new value of the means is conducive to the new value of the goal (Walsh 2013, p. 52). In the example discussed above, we can see these two patterns of stability in the counterfactual condition in which you are too busy to walk to the market and the one in which a different store carries the lemons respectively. Since your action of going to the market is directed toward the goal of buying lemons from the store, under certain conditions - e.g., being busy during the dayyou would adjust your action — e.g., by driving instead of walking — such that you would still buy the lemons. Similarly, if certain aspects of your goal-e.g., which stores the lemons are to be bought at—change, you would adjust your action-e.g., by going to a different store insteadsuch that you would still buy the lemons.

As we can see above, Walsh's account of purposive invariance makes reference to the notion of a goal. But it's worth noting that, in offering an account of teleological explanation, Walsh is 
not concerned with giving an account of what it is for something to be goal-directed, but is rather trying to identify the aspects of goal-directness that make it explanatory. Here, we may simply understand goals based on the notion of goal-directedness in Cybernetics and Systems Theory (Rosenblueth, Wiener, \& Bigelow, 1943; Bertanlanffy, 1969; Braithwaite, 1964; Nagel, 1961; 1977; Sommerhoff, 1950). ${ }^{15}$ On this account, having a goal is a complex, empirically observable property of a goal-directed system that results from the system's architecture and causal capacities. A goal-directed system is, roughly, a system that has the capacity to attain and maintain an endstate in the face of external and internal perturbations. When changes in the external or internal environment threaten to deflect the system from this end-state, the system typically alters its behavior in a way that redirects the system toward this state. The stable end-state is the system's goal. Since goal-directed systems don't always maintain their goal states successfully, the account only requires that the system oscillates around its goals or approaches them asymptotically. Thus, goal-directedness can be characterized in terms of behavioral signs such as persistence and/or plasticity. Persistence involves maintaining the end-state across a wide range of conditions; and plasticity means doing so by responding differently to conditions and in a manner appropriate to attaining the end-state in each. On any occasion, a plastic system has a 'repertoire' of responses that it is capable of producing, some of which are conducive to the attainment of the system's goals. And it exhibits a bias toward the goal-conducive elements of its repertoire (Walsh, 2012, p. 177).

Note that although the paradigm cases of successful teleological explanation appeal to the intentions of an agent, having a goal in Walsh's intended sense does not presuppose intentionality. Non-human organisms and other systems without intentional states can exhibit goal-directed behavior just as rational agents do. In fact, Walsh considers many biological subsystems such as the endocrine, immune, and thermoregulatory systems to be goal-directed systems, as they involve persistent and/or plastic attainment of stable end-states (2015, p. 202).

${ }^{15}$ Although Walsh offers a different, non-reductive account of goals - in terms of an interdefineable cluster of concepts consisting of goal, affordance, and repertoire-elsewhere (2015, p. 211), in his discussion of teleological explanation, he appeals to the system-theoretical notion of goal-directedness as a "natural and observable" feature of a system's dynamics (2015, p. 195). 
Moreover, it's worth noting that the invariance relation between a system's goal $x_{e}$ and a means $x_{c}$ to achieving it does not require that the goal state is achieved successfully. The relation of counterfactual dependence between $x_{e}$ and $x_{c}$ does not require that they actually occur, but rather that there are a range of actual or counterfactual conditions in which $x_{c}$ occurs as a matter of regularity in a way that is conducive to $x_{e}$. To see an example, suppose I have the goal of buying sweet lemons, but ultimately fail to buy them because the store runs out of them before I get there. Even though my goal state of buying lemons is not actually realized, we can see that it still has an invariant relation to my action of going to the market. There are a range of counterfactual conditions in which the store does not run out of lemons before I get there, and in which I buy lemons. And my behavior in these counterfactual conditions shows persistence and plasticity toward the goal of buying lemons such that in each condition I adjust my action in such a way that it is conducive to the goal of buying lemons.

Walsh's account of teleological explanation is compelling. It offers a plausible view of what makes teleological explanation explanatory, and shows how causes and goals explain in the same way - namely by uncovering patterns of counterfactual dependence-despite offering distinct explanations. More importantly for our purposes, Walsh's account identifies a kind of regularity that has explanatory significance and is empirically observable in an individual system. This particular kind of regularity in the modal profile of a goal-directed system will be the core of my account of natural goodness. As I will argue in the next section, patterns of purposive invariance can replace the generic patterns of regularity in the natural-historical account, and give us an alternative account of natural goodness that does not involve a commitment to anti-individualism.

\section{A Modal-Explanatory Account of Natural Goodness}

In a nutshell, my account of natural goodness uses Walsh's patterns of purposive invariance to determine what is characteristic in the life of a living organism without appealing to the natural history of its life-form. I argue that whether the contribution of a part or aspect of an organism to a good like survival is accidental or characteristic depends on whether there are patterns of counterfactual dependence that enable us to explain the part or aspect as a means toward the goal of survival. Thus, on my account, the natural good of an organism depends on the patterns of purposive invariance observed in the organism's own modal profile, and not on the generic patterns observed across the members of its life-form. 
Before presenting the account in detail, there is an issue that I need to clarify in relation to my use of Walsh's account to teleological explanation. I mentioned earlier that the notion of goal implicit in Walsh's account can be understood based on the systems-theoretic notion of goaldirectedness. However, since the system-theoretic account is given in causal terms, it characterizes any physical system that tends toward some steady state of equilibrium in the right way as a goaldirected system. As a result, the account extends the concept of goal to many systems that nobody would consider to be genuinely goal-directed. As Bedau (1992) has argued, for instance, many equilibrium systems such as a damped pendulum or a marble inside a bowl tend toward a steady state of rest in a way that meets the criteria of the systems-theoretic account, and yet we do not consider such systems to be goal-directed. ${ }^{16}$ Now, if the system-theoretical approach fails to exclude non-goal-directed systems that merely behave as if they were goal-directed, Walsh's account of teleological explanation similarly extends these explanations to systems that merely exhibit the behavioral signs of a goal-directed system. So, the modal profile that Walsh calls purposive invariance is not a sufficient condition for genuine purposive behavior. ${ }^{17} \mathrm{We}$ may call this modal profile perseverance to avoid the implication of genuine purposiveness. What perseverance involves is a persistent and/or plastic tendency toward an end-state, which only amounts to a necessary condition for purposiveness at best. Thus, perseverance on its own is clearly not sufficient for determining standards of natural goodness. Just because a system perseveres toward an end-state, it doesn't follow that it can be evaluated based on whether this end-state is achieved. A pendulum whose bob is kept from returning to the state of rest is not

${ }^{16}$ Specifying criteria that exclude non-goal-directed equilibrium systems turns out to be a serious problem for the systems approach, which has led many to conclude that this approach ultimately fails to differentiate between genuine goal-directed systems and systems that merely behave as if they were goal-directed. Bedau (1992), for instance, argues that the causal dynamics of a system do not determine whether the system is goal-directed. He proposes that a distinctive feature of goal-directed systems is that their behavior is of value to something or someone, which is why the systems approach fails to capture goal-directedness in terms of merely causal, quantitative criteria.

${ }^{17}$ As I mentioned earlier, it is not the aim of Walsh's account of teleological explanation to offer an understanding of genuine goal-directedness, but rather to identify the aspects of goal-directedness that make it explanatory. So the concern that I am raising here is not necessarily a problem for Walsh's view. It's rather a concern about whether we can use Walsh's view regarding teleological explanation as a basis for an account of natural goodness. 
thereby failing or defective, since there is no value associated with the state of rest to begin with. This means that if we are to give an account of natural goodness based on the notion of perseverance, we will have to supplement the account with additional criteria that can mark the difference between genuinely purposive and non-purposive cases.

Because of this, it is not the ambition of my account to determine standards of natural goodness based on perseverance alone. I merely use the patterns of perseverance to replace the patterns of genericity in the natural-historical account. As we saw in section 2, patterns of genericity-i.e., the patterns of regularity underlying generic judgments-are not inherently evaluative either. Foot and Thompson supplement the criterion of genericity with additional, evaluative criteria, which makes the natural-historical account a non-reductive account that needs to be coupled with basic general assumptions about the good of living things to issue further evaluations. As we will see below, my account of natural goodness is similarly non-reductive, as it too involves evaluative criteria. I will argue that my account also enables us to turn general plausible assumptions about the good of living things into specific standards of evaluation, and explains the relation between these evaluations and empirical observation. Nonetheless, I will show that my account does all of this without making any reference to genericity, and therefore does not share the problematic anti-individualistic implications of the natural-historical account.

The Modal-Explanatory Account is as follows:

For any individual organism $x$, being/doing/having $F$ is a natural good if and only if:

(1) Teleology(EXP): If $x$ were to be/do/have $F, x$ 's being/doing/having $F$ would teleologically explain $H$ and be teleologically explained by $G$, where $H$ and $G$ are natural goods in $x$.

(2) Independence (EXP): The teleological explanation of $F$ by $\mathrm{G}$ and the teleological explanation of $H$ by $F$ would be independent of the goods of any entity other than $x$.

Note that I have used the subscript (EXP) to indicate that the conditions are defined in terms of teleological explanation.

Let's look at the components of the account in turn. The first condition captures the idea that the natural goods of a living organism are teleologically interconnected. $F$ is a natural good of the organism if and only if, on one hand, there is another natural good of the organism, $G$, such that $F$ would be a means toward $G$, and on the other hand, there is another natural good of the organism, $H$, which would be a means toward $F$. Much like the condition of Teleology in the naturalhistorical account, Teleology(EXP) presupposes a prior, evaluative conception of the life of the 
organism. Recognizing a natural good of organism $x$ requires presupposing at least some other natural goods of $x$. But here, instead of understanding the means-end relation between the natural goods in terms of generic statements featuring the 'in order to' clause, this relation is understood in terms of teleological explanation and the kind of modal profile that it involves. On my account, if $P$ is a means toward $Q$, then $P$ is teleologically explained by $Q$, where teleological explanation is understood in terms of Walsh's account discussed earlier. Thus, Teleology(EXP) requires that there would be a counterfactual dependence relation of perseverance between $F$ and $G$ and between $H$ and $F$.

It's worth noting that the condition expressed in Teleology(EXP) does not require that $x$ actually is/does/has $F$. In other words, $F$ can be a natural good for $x$ even if it is not achieved in $x$. By the same token, $G$ or $H$ can be a natural good for $x$ even if they are not achieved in $x$. What the condition requires is rather that if $x$ were to be/do/have a natural good like $F$, its being/doing/having $F$ would fit in patterns of perseverance involving other natural goods like $G$ and $H .{ }^{18}$ This is how the account allows for the occurrence of natural defect in an organism, i.e., cases where the organism lacks something that is a natural good. On the natural-historical account, this possibility simply follows from the logic of generic statements: "tigers run fast" and "tigers run fast in order to hunt prey" can be true even if a particular tiger is unable to run fast. On the modal-explanatory account, the possibility of defect is captured by the consideration that even if $x$ lacks $F$, it can be true that the modal profile of $x$ is such that, on the one hand being/doing/having $F$ would make a persistent and/or plastic contribution toward $G$, and on the other hand $H$ would make a persistent and/or plastic toward being/doing/having $F$. For example, even in a tiger that as a matter of fact cannot run fast due to an injury, it can be true that if it had the ability to run fast, this would make a persistent and/or plastic contribution toward hunting prey, such that we would teleologically explain the tiger's running fast as a means toward hunting prey. Similarly, it can be true that other

18 These conditions are given with the help of a counterfactual. Here I have left it open how the counterfactual should be interpreted. But any theory of counterfactuals could be used to fill in the details of the account. For instance, if we use Lewis's (1973) theory, the condition of Teleology (EXP) would require that some possible world where $x$ is/does/has $F$ and this is teleologically explained by $G$ is closer to the actual world than any of those possible worlds where $x$ is/does/has $F$ but this is not teleologically explained by $G$. 
aspects of the life of such a tiger, like having four legs, would make a persistent and/or plastic contribution toward running fast, even if running fast is not actually achieved.

The second condition, Independence $\left(\mathrm{EXP}_{)}\right.$, captures the idea that evaluations of natural goodness are distinct from evaluations of artifacts and crafts in that they do not depend on the interests of us or any beneficiaries external to the system. We saw that on the natural-historical account this criterion is formulated in terms of whether anyone needs to actually make the relevant natural-historical judgments. On the modal-explanatory account, the idea is formulated in terms of teleological explanation. In the case of artifacts and crafts, the teleological explanation of a given feature or part of the system ultimately goes beyond the system itself. That is because what ultimately underwrites the teleological relations that hold between the parts and mechanisms of an artifact is the fact that it is a means toward our ends. A car's carburetor, for instance, can be teleologically explained as a means toward the end of mixing air and fuel in the proper air-fuel ratio for combustion. ${ }^{19}$ The mixing of air and fuel is in turn teleologically explained as a means toward the combustion of the fuel, which is itself a means toward moving the car. But the explanation ultimately depends on what is good for $u s$. What underwrites the status of the moving of the car as an end is the fact that it is a means toward our end of transportation. In other words, the complete teleological explanation of the carburetor will have to make reference to our goods and interests. In contrast, in the case of living organisms, the teleological explanation of the system's parts and processes will be independent of the goods of any entity other than the system itself. To use our earlier example, a tiger's ability to run fast can be explained as a means toward the goal of hunting prey. This goal in turn can be teleologically explained in terms of further goods such as nutrition and survival. But the chain of teleological relations does not have to go beyond the goods of the tiger itself for the explanation to be complete. ${ }^{20}$ As we saw earlier, the natural

\footnotetext{
${ }^{19}$ Note that the carburetor has the right modal profile for teleological explanation. Under a range of conditions, it mixes air and fuel in the ratio that is appropriate for combustion regardless of, for instance, how much fuel is in the tank.

20 The claim here is not about the causal explanations that apply in the case of an organism. The causal explanation of an organism's parts and aspects can very much depend on the goods of external entities-for instance, if it is an organism that we have artificially bred to serve interests of our own. The claim is rather that the teleological
} 
goods of the organism instantiate teleological relations that form a cycle. So even though each natural good is teleologically explained in terms of another natural good, we don't need to leave the cycle of the goods of the organism to complete the explanation. ${ }^{21}$

Now we can see how the modal-explanatory account compares to the natural-historical account in making evaluations of natural goodness and defect. Consider again Lott's case of a tiger with an unusual arrangement of fur on its face resembling a hunter's mother's face. The naturalhistorical account explains why this feature is not a natural good by appealing to the fact that it is neither characteristic of tigers in general to have it, nor characteristic of this feature to contribute to tigers' survival. In contrast, the modal-explanatory account explains the fact that this feature is not a natural good in a very different way, by appealing to the modal profile of the very tiger that has the unusual face. Although the arrangement of fur on the face of the tiger happens to make a contribution toward survival, this contribution is not part of a persistent and/or plastic pattern of contribution toward survival. Neither are there other natural goods in the life of the tiger that persevere toward creating that specific arrangement of fur. The relation between the arrangement of fur and other natural goods in the life of the tiger is contingent and merely causal. In other words, it's similar to the case of buying sweet lemons as a result of accidentally finding them in the store as opposed to going to the store with the goal of buying sweet lemons.

According to the modal-explanatory account, a tiger's modal profile also explains why certain other features such as the ability to run fast or having night vision are natural goods in the tiger's life. Consider a tiger's night vision, which contributes to hunting prey and obtaining food. In contrast to the unusual arrangement of fur in Lott's example, the ability to see in the dark can be viewed a genuine means toward the good of survival, because the contribution it makes toward survival is persistent and plastic. It is not just that it enables the tiger to obtain food in a one-off

explanation of these parts and aspects as means towards the natural goods of the organism is independent of the goods of external entities.

${ }^{21}$ Note that this doesn't require that all the goods of an organism are placed on a single cycle, but rather that there is at least one cycle, exclusively consisting of the goods of the organism, that they are part of. Because of this, not every natural good of the organism has to be a means toward survival or reproduction in order to be part of a cycle. Human character traits that constitute different virtues, for instance, can be part of a cycle of virtuous traits that are interdependent without necessarily contributing to survival. 
case under highly contingent circumstances. There are a range of actual and counterfactual conditions in which having night vision would contribute to the tiger's hunting prey and obtaining food. Moreover, there are other parts and aspects of the tiger, such as having more rods than cones in their eyes and having a tapetum lucidum (a reflective layer behind the retina), which fit in a persistent and plastic pattern of contribution toward creating night vision. In fact, as I explained above, the modal-explanatory account has no problem identifying this good in a tiger that actually lacks the ability. Even if a tiger's night vision is compromised due to an injury or a congenital problem, it can still be the case if the tiger were to have the ability, this would be a means toward the goods of hunting prey and obtaining food. And there would still be other parts and aspects of the tiger that persevere toward creating night vision, even if unsuccessfully. ${ }^{22}$

Moreover, although the modal-explanatory account allows us to identify natural goods that are missing in an organism due to a defect, it does not characterize just any possible feature that would be potentially beneficial as naturally good. In the case of a tiger, for instance, having wings and the ability to fly might be beneficial and enable the organism to achieve its ends more successfully. But this doesn't mean that this is a natural good in the life of a tiger, or that a tiger is defective for not having wings. The modal-explanatory account can explain why a tiger without legs is defective while a tiger without wings is not by appealing to the modal profile of an individual tiger. If having wings was a natural good in the life of a tiger, there would be other aspects of a tiger's life that persevere toward having wings and would be teleologically explained as a means toward this end. But a tiger's anatomy and morphology simply do not have the right modal profile to meet this condition. The parts and aspects of a tiger's anatomy and morphology are best explained as means toward locomotion by walking and running as opposed to flight.

Finally, note that unlike the natural-historical account, the modal-explanatory account is not committed to the idea that all members of a species need to be evaluated based on the same standard. It is in principle possible for different individual members to have different modal profiles, resulting in different standards of evaluation. To see this, consider again the case of Hopper-the goat that has adapted to its condition by developing enlarged hind limbs, a curved

\footnotetext{
${ }^{22}$ Note that the account does not consider $F$ a natural good if no part or aspect of the organism perseveres toward $F$. For instance, if all the parts and aspects of the visual system that distinctively contribute toward night vision are missing in a tiger, the account would not characterize night vision as a natural good in such a tiger.
} 
spine, and an unusually large neck, enabling it to walk and run by using its hind legs alone. As a result of these adjustments, the modal profile of Hopper perseveres toward moving around by walking on two legs. It is not that the two legs make a one-off contribution to the goat's moving around under highly contingent circumstances. Rather, due to the goat's anatomy, having two legs fits into a system of locomotion that makes a persistent and plastic contribution toward moving with two legs. This is why, on the modal-explanatory account, having two legs can be characterized as a natural good in the life of Hopper, even though it might amount to a natural defect in the life of other goats. Note that on this account, having four legs is actually not a natural good in the life of Hopper, for the same reason that having wings or fins is not a natural good in its life. The modal profile of Hopper does not persevere toward having such characteristics and using them toward obtaining its goods. The goat's anatomy is simply not a means toward walking on four legs, just as it is not a means toward flying or swimming. It's rather a means toward walking and hopping on two legs, which is why for Hopper natural good consists in having two legs rather than four. We may contrast the case of Hopper with a more ordinary goat that has lost two legs in an injury or is born with two legs due to a congenital condition without having been able to adjust to having two legs during development. Such a goat does not have enlarged hind limbs or a curved spite, and so is not capable of hopping on two legs. Its modal profile actually perseveres toward having four legs, even though it only has two. Unlike Hopper, such a goat is defective in that it fails to have four legs, because what is naturally good in its life is having four legs rather than two.

Thus, the modal-explanatory account makes the same evaluations as the natural-historical account in cases where these evaluations are intuitively plausible. Yet it makes different evaluations in the case of individuals with uniquely adaptive adjustments where the naturalhistorical account issues the wrong assessment due to its commitment to anti-individualism. In other words, what we have here is a viable alternative to the natural-historical account that does not share its problematic, anti-individualistic implications.

\section{Concluding Remarks: Natural Goodness without Anti-Individualism}

I started this paper by highlighting the distinction between the general concept of natural goodness and the specific, natural-historical conception of this concept implicit in Foot and Thompson's account. I argued that the natural-historical account is anti-individualistic and issues implausible evaluations of individuals with uniquely adaptive adjustments. I then argued that the modal- 
explanatory account is a viable alternative to the natural-historical account that makes intuitively plausible evaluations even in the case of such individuals.

It's worth noting that the modal-explanatory account also issues a more intuitively plausible verdict in Swampman-style cases. As we saw earlier, the natural-historical account implies that upon discovering Swampman's ontogeny, we can exclude the possibility that it's a living thing and we can treat it as if it has no natural good or welfare. In contrast, the modal-explanatory account allows for the possibility that Swampman could be a living thing and subject to evaluations of natural goodness. Unlike the natural-historical account, this account has the resources to explain why in the case of Thompson's swamp double its molecular equivalents of human arms are really arms and not deformed wings. Since the creature is a molecule-by-molecule replica of a human, its modal profile is exactly like that of a human. So the explanation of its parts and aspects will be exactly the same: its molecular equivalents of human arms are arms rather than wings, because its anatomy and structure persevere toward using arms rather than wings.

Not only does the modal-explanatory account give an intuitive assessment of the cases discussed above, it also has desirable implications regarding our understanding of human form in particular. On one hand, the account allows for a pluralistic conception of human form, where different individual human beings can potentially have different forms that give rise to different standards of evaluation. On the other hand, the standard of evaluation for each individual is grounded in facts about the individual itself rather than facts about the species the individual happens to be born into. This pluralist and individualist conception of human form is desirable for many reasons, but a particularly salient one is that it enables us to present a more nuanced view of human disability.

One of the objections raised against Foot's version of neo-Aristotelian naturalism is that it labels the lack of any species-typical ability in human beings as a defect, while it's not clear at all that departure from a species-typical ability necessarily makes a disabled person defective (Woodcock, 2006, p. 451). Many philosophers defend a value-neutral view of disability, according to which the lack of a physical or mental ability that other people have is a neutral feature that that is not in itself bad. Barnes $(2014 ; 2016)$, for instance, argues that having a disability is a mere difference from others. It is a difference that makes you a minority, but it does not necessarily make you worse off because of the difference. Defenders of the value-neutral view don't deny that having a disability — in the sense of lacking an ability possessed by 'normal' people — can involve 
the loss of some goods or that it can ultimately result in being worse off. But they argue that the relation between having the disability and being worse off is highly contingent and socially constructed. Moreover, they argue that precisely what makes you lose out on some goods can allow you to participate in other goods that are unique to disability. It might be true, for instance, that the ability to hear is a good that deaf people lack. But there are other goods, such as the unique experience of a signed language as first language, which deaf people enjoy instead. ${ }^{23}$

The natural-historical account makes it difficult to accommodate such a view of disability due to its commitment to the idea that the standards of goodness are necessarily shared across the members of a life-form. Consider a person with a disability such as deafness from birth, who is perfectly happy as a deaf person, embraces being deaf, and participates in the unique set of goods that come with this identity. On the natural-historical account, lacking the ability to hear amounts to a defect, because "humans have a sense of hearing" is, quite plausibly, a true natural-historical judgment. Yet, it's not obvious that the deaf person in our example should be viewed as naturally defective merely because "humans have a sense of hearing". In contrast to the natural-historical account, the modal-explanatory account can avoid systematically treating every case of deafness as a defect, because on this account the basis for evaluation is the modal profile of the individual person. And it's at least in principle possible for the physical and social aspects of the life of a deaf person to be arranged in such a way that deafness does not constitute a natural defect in their life. Of course, this is merely scratching the surface on the topic of disability and human form. I have neither offered a conclusive defense of the value-neutral view of disability, nor shown that the natural-historical account has no way of accommodating such a view. I have only presented a few rudimentary considerations to illustrate how the fact that the modal-explanatory account is consistent with individualism can work in its favor when it comes to offering an understanding of human form.

In summary, I have offered an alternative basis for evaluations of natural goodness that avoids at least one problematic aspect of Foot and Thompson's paradigmatic account. On my account, what determines evaluations of natural goodness are the patterns of counterfactual

${ }^{23}$ In fact, over the last few decades, disability rights activists have advocated an affirmative conception of disability (Swain \& French, 2000), according to which disability is a positive social identity that can be actively embraced and celebrated. 
dependence among the parts and aspects of an organism that underwrite teleological explanations of these parts and aspects. Instead of relying on generic judgments about a species, this account grounds the distinction between goodness and defect in an explanatorily significant type of modal profile that is instantiated in an individual organism. Thus, what I have offered is an account of natural goodness that is consistent with individualism and in line with the diversity and plasticity that is manifest everywhere in realm of living things.

Acknowledgements: I would like to thank Sergio Tenenbaum, Denis Walsh, Philip Clark, Tristram McPherson, Andrew Sepielli, John Hacker-Wright, and Brendan de Kenessey, as well as an anonymous referee at this journal, whose comments on earlier drafts significantly improved the quality of this paper. I am also grateful to the audiences at York University and University of Cincinnati's Departments of Philosophy for helpful discussion.

\section{References}

Amundson, R. (2000). Against normal function. Studies in History and Philosophy of Biological and Biomedical Sciences 31(1), 33-53. doi.org/10.1016/S1369-8486(99)00033-3

Andreou, C. (2006). Getting on in a varied world. Social Theory and Practice, 32, 61-73. doi.org/10.5840/soctheorpract20063213

Barnes, E. (2014). Valuing disability, causing disability. Ethics, 125(1), 88-113. doi: $10.1086 / 677021$

Barnes, E. (2016). The minority body: a theory of disability. Oxford University Press.

Bedau, M. (1992). Where's the good in teleology? Philosophy and Phenomenological Research, 52, 781-806. doi: 10.2307/2107911

Bertanlanffy, L. (1969). General systems theory. New York: Braziller.

Braithwaite, R. B. (1964). Scientific explanation: a study of the function of theory, probability and law in science. Cambridge University Press.

Fitzpatrick, W. J. (2000). Teleology and the norms of nature. Taylor \& Francis.

Foot, P. (2001). Natural goodness. Oxford University Press. 
Godfrey-Smith, P. (1994). A modern history theory of functions. Noûs, 28, 344-62. doi.org/10.2307/2216063

Hacker-Wright, J. (2009). What is natural about Foot's ethical naturalism? Ratio, 22, 308-321. doi.org/10.1111/j.1467-9329.2009.00434.x

Hursthouse, R. (1999). On virtue ethics. Oxford University Press.

Lewens, T. (2010). Foot note. Analysis, 70, 468-473. doi.org/10.1093/analys/anq036

Lewis, D. (1973). Counterfactuals. Harvard University Press.

Lott, M. (2012a). Have elephant seals refuted Aristotle? Nature, function, and moral goodness. Journal of Moral Philosophy, 9, 353-375. doi.org/10.1163/174552412X625727

Lott, M. (2012b). Moral virtue as knowledge of human form. Social Theory and Practice, 38, 407431. doi.org/10.5840/soctheorpract201238323

Maguire, B. (2017). The autonomy of ethics. In: T. McPherson, D. Plunkett (Ed.) The Routledge Handbook of Metaethics (pp. 431-442). Routledge.

Millikan, R. G. (1989). In defense of proper functions. Philosophy of Science, 56(2), 288-302. doi.org/10.1086/289488

Millgram, E. (2009). Life and action. Analysis, 69, 557-564. doi.org/10.1093/analys/anp087

Millum, J. (2006). Natural goodness and natural evil. Ratio, 19, 199-213. doi.org/10.1111/j.14679329.2006.00320.x

Moosavi, P. (2019). From biological functions to natural goodness. Philosophers' Imprint, 19 (51), 1-20.

Nagel, E. (1961). The structure of science: problems in the logic of scientific explanation. Harcourt, Brace \& World.

Nagel, E. (1977). Teleology revisited. Journal of Philosophy, 84, 261-301. doi: 10.2307/2025807

Neander, K. (1991). Functions as selected effects: the conceptual analyst's defense. Philosophy of Science, 58, 168-84. doi.org/10.1086/289610 
Odenbaugh, J. (2017). Nothing in ethics makes sense except in the light of evolution? Natural goodness, normativity, and naturalism. Synthese, 194, 1031-1055. doi.org/10.1007/s11229015-0675-7

Rosenblueth, A., Wiener, N., \& Bigelow, J. (1943). Behavior, purpose and teleology. Philosophy of science, 10, 18-24. doi.org/10.1086/286788

Sommerhoff, G. (1950). Analytic biology. Cambridge: Cambridge University Press.

Swain, J., \& French, S. (2000). Towards an affirmation model of disability. Disability \& society, 15(4), 569-582. doi.org/10.1080/09687590050058189

Thompson, M. (1995). The representation of life. In: R. Husthouse, G. Lawrence, \& W. Quinn (Eds.) Virtue and Reasons (pp. 247-296). Oxford: Clarendon Press.

Thompson, M. (2004). Apprehending human form. In: A. O'Hear (Ed.), Modern moral philosophy (pp. 47-74) Cambridge: Cambridge University Press.

Thompson, M. (2008). Life and action: elementary structures of practice and practical thought. Harvard University Press.

Walsh, D. (2012). Mechanism and purpose: a case for natural teleology. Studies in History and Philosophy of Biological and Biomedical Sciences, 43, 173-181. doi.org/10.1016/j.shpsc.2011.05.016

Walsh, D. (2013). Mechanism, emergence, and miscibility: the autonomy of evo-devo. In: P. Huneman (Ed.) Functions: Selection and Mechanisms (pp. 43-65). Dordrecht: Springer.

Walsh, D. (2015) Organisms, agency, and evolution. Cambridge University Press.

West-Eberhard, M. J. (2003). Developmental plasticity and evolution. New York: Oxford University Press.

West-Eberhard, M. J. (2005). Developmental plasticity and the origin of species differences. Proceedings of the National Academy of Sciences, 102 (suppl. 1), 6543-6549. doi.org/10.1073/pnas.0501844102

Woodcock, S. (2006). Philippa Foot's virtue ethics has an Achilles' heel. Dialogue, 45, 445-468. doi.org/10.1017/s0012217300001013 
Woodward, J. (2001). Law and explanation in biology: invariance is the kind of stability that matters. Philosophy of Science, 68(1), 1-20. doi.org/10.1086/392863

Woodward, J. (2005). Making things happen: a theory of causal explanation. Oxford university press. 